\title{
Facilitators and Barriers to Detection and Treatment of Depression, Anxiety and Experiences of Domestic Violence in Pregnant Women Attending Midwife Obstetric Units (MOUs) in Cape Town, South Africa: A Qualitative Study
}

Zulfa Abrahams ( $\nabla$ zulfa.abrahams@uct.ac.za )

Alan J Flisher Centre for Public Mental Health, University of Cape Town

Sonet Boisits

Alan J Flisher Centre for Public Mental Health, University of Cape Town

Marguerite Schneider

Alan J Flisher Centre for Public Mental Health, University of Cape Town

Simone Honikman

Alan J Flisher Centre for Public Mental Health, University of Cape Town

Crick Lund

Alan J Flisher Centre for Public Mental Health, University of Cape Town

\section{Research Article}

Keywords: barriers, facilitators, depression, pregnant, health system, healthcare

Posted Date: December 21st, 2021

DOI: https://doi.org/10.21203/rs.3.rs-512424/v3

License: (c) (1) This work is licensed under a Creative Commons Attribution 4.0 International License.

Read Full License 


\section{Abstract \\ Background}

In South Africa, symptoms of common mental disorders (CMDs) such as depression and anxiety are highly prevalent during the perinatal period and linked to experiences of domestic violence. However, limited routine detection and treatment is available to pregnant women with these problems, even though evidence suggests that screening and treating CMDs during pregnancy improves the health and economic outcomes of mothers and their children, and has been suggested as a key approach to improving the health of perinatal women and children. We investigated facilitators and barriers of serviceproviders and service-users in detecting and treating pregnant women with symptoms of CMDs and experiences of domestic violence.

\section{Methods}

This study was conducted in four midwife obstetric units (MOUs) in Cape Town, South Africa, and in the NPOs providing community-based support in the communities surrounding the MOUs. Service-provider perspectives were informed by qualitative interviews with 37 healthcare workers providing care to pregnant women. Qualitative interviews with 38 pregnant women attending the same MOUs for their first antenatal care visit provided service-user perspectives.

\section{Results}

Facilitators identified included the availability of a mental health screening questionnaire and the perceived importance of detection and treatment by both service-providers and -users. Barriers contributing to the low detection rates included service-users concerns about the lack of confidentiality and feelings of shame related to experiences of domestic violence as well as service providers discomfort in dealing with mental health issues, their limited time available and heavy patient load. In addition, service-providers highlighted the lack of standardised referral pathways and the poor uptake of referrals by women with symptoms of depression and anxiety, or experiences of domestic violence

\section{Conclusions}

While the system-level barriers need to be addressed at a policy level, the patient- and provider-level barriers identified indicate the need to strengthen health systems by training antenatal care nurses to detect symptoms of CMDs and experiences of domestic violence in pregnant women, developing standardised referral pathways and training lay healthcare workers to provide treatment for mild symptoms of depression and anxiety. 


\section{Background}

Common mental disorders (CMDs), such as depression and anxiety, are highly prevalent during the perinatal period, with low- and middle-income countries (LMIC) carrying the greatest burden. It is estimated that in LMIC, $18 \%$ of perinatal women experience depression [1] and $34 \%$ experience anxiety [2]. In South Africa, the prevalence of depressive symptoms during pregnancy ranges between $27 \%$ and $39 \%[3-6]$, while symptoms of anxiety range between $15 \%$ and $23 \%[3,7]$. Antenatal depression is associated with adverse infant and child outcomes, such as preterm birth, low birth weight, infant stunting and underweight children [8-10]. In LMIC, evidence suggests that screening and treating CMDs during pregnancy improves the health and economic outcomes of mothers and their children [11, 12], and has been suggested as a key approach to improving the health of perinatal women and children in South Africa [13].

As a result of a growing awareness of the burden of disease and economic costs associated with mental disorders, South Africa adopted the Mental Health Policy Framework and Strategic Plan 2013-2020 [14] which aligns with the WHO Mental Health Action plan [15]. However, having a new policy framework supporting the integration of mental health into primary healthcare [16] has not led to the desired changes in service delivery, and the detection of symptoms of CMDs continue to be excluded from routine care provided at public healthcare facilities in South Africa [17].

Little is known about the facilitators and barriers to detection, referral and treatment of pregnant women with depression, anxiety and experiences of domestic violence in public sector healthcare facilities in South Africa. The Health System Strengthening in sub-Saharan Africa (ASSET) study [18] has undertaken to work with the Western Cape Department of Health $(\mathrm{DoH})$ to develop and evaluate the impact of a screening, referral and counselling intervention for pregnant women with CMDs and experiences of domestic violence. As part of the development of the intervention, this study investigated the facilitators and barriers to detecting and treating pregnant women with symptoms of CMDs and experiences of domestic violence attending public sector healthcare facilities in Cape Town.

\section{Methods}

\section{Setting}

In South African primary healthcare (PHC) facilities, antenatal care is provided by nursing staff as well as lay healthcare workers, like HIV and breastfeeding counsellors. The DoH also funds non-profit organisations (NPOs), mandated to provide facility-and community-based support to patients attending PHC facilities. NPOs employ teams of lay community health workers (CHWs) who are managed by professional nurses, called outreach team leaders (OTL).

This qualitative study was conducted in midwife obstetric units (MOUs) and in the NPOs providing community-based support to them. All MOUs are situated on the 'Cape Flats' [19] - a large, flat area covered by sandy soil on the outskirts of the city of Cape Town, and offer free antenatal, birthing and 
postnatal services to pregnant women. The area consists of Black townships and Coloured (people of mixed ancestry [20]) ghettos where these communities were forcibly moved to because of Apartheid laws in South Africa. Communities experience high levels of unemployment, poverty [21], substance abuse [22], gang violence [23] and domestic violence [24].

\section{Data collection}

Healthcare workers providing care to pregnant women, working in four MOUs or the supporting NPOs, were purposively selected and recruited between August and December 2019. The following cadres of healthcare workers were invited to participate in semi-structured interviews: operational managers, antenatal care (ANC) nurses, breastfeeding counsellors, HIV counsellors, health promotion officers, mental health nurses, social workers, CHWs and OTLs. All except one health promotion officer agreed to participate in the study.

During November 2019 and June 2020, pregnant women attending MOUs for their first antenatal appointment were invited to participate in the study. Those who consented were screened for symptoms of CMDs using the Edinburgh Postnatal Depression Scale (EPDS) [25] and a psychological distress questionnaire [26]. In addition, participants were screened for experiences of domestic violence, which used a 12-month recall period and asked about experiences of verbal or emotional abuse (e.g., shouting or swearing, name calling, insulting, threats of intimidation, ignoring or excluding, isolating, humiliating, blaming), physical abuse (e.g., beating, pushing, kicking, biting, slapping) and sexual abuse (e.g., forced sexual intercourse or intercourse without your consent). The EPDS, using a 7-day recall period, has been validated in South Africa with a cut-off $\geq 13$ indicating a probable CMD $[25,27,28]$. The psychological distress questionnaire comprised three mood questions [26], derived from the Whooley scale [29], the Generalised Anxiety Scale (GAD-2) [30], and the EPDS [25], uses a two-week recall period, and was validated against the EPDS. It was found to correctly classify $91 \%$ of women using a cut-point of $\geq 2$ (sensitivity=85.7; specificity=92.9) [26]. Pregnant woman who scored $\geq 13$ on the EPDS, $\geq 2$ on the psychological distress questionnaire or $\geq 2$ on the domestic violence questionnaire were invited to participate in a semi-structured interview. Recruitment continued at all facilities until saturation was reached.

English language, semi-structured interview guides were developed, and translated to Afrikaans and IsiXhosa by bilingual experts. The interviews were administered by trained researchers in English, Afrikaans and IsiXhosa, took between 30 and 60 minutes to complete, and were audio-recorded. All interviews were conducted in a private space, with no others present, to ensure confidentiality. Healthcare workers were asked about their role and attitude to detecting, referring and treating pregnant women with symptoms of depression or anxiety, and experiences of domestic violence (Supplementary File 1). Pregnant women were asked about their understanding of depression, anxiety and experiences of domestic violence, and their perceived reasons for experiencing psychological distress (Supplementary File 2). All participants were asked about their thoughts on the acceptability and feasibility of a routine screening and counselling service for pregnant women. 


\section{Data analysis}

The semi-structured interviews that were conducted in English were transcribed verbatim, while interviews conducted in Afrikaans or IsiXhosa were translated into English and transcribed by bilingual speakers. A framework analysis approach [31] was used to analyse the transcripts. The development of initial codes was guided by the semi-structured interview topics. Further themes not captured by the initial coding were identified through extensive reading of the transcripts and coding passages interpreted as important. Transcripts and data were managed using NVivo 12 Pro qualitative data analysis software (QSR International Pty Ltd) [32].

Ten percent of the healthcare workers transcripts were randomly selected for analysis by three researchers, and the inter-rater reliability assessed (agreement $=78.4 \%$; Gwet's agreement coefficient (AC) $[33,34]=0.7329)$. Coding disagreements were discussed and resolved. Thereafter, each of the three researchers analysed a third of the remaining transcripts.

Similarly, $10 \%$ of the pregnant women's transcripts were randomly selected for analysis by two researchers, and the inter-rater reliability assessed (agreement $=87.3 \%$; Gwet's AC=0.8547). Coding disagreements were discussed and resolved. Thereafter, each researcher analysed half the remaining transcripts.

\section{Ethical approvals}

Ethical approval for the study was obtained from the Human Research Ethics Committee at the University of Cape Town (Ref No: 139/2018) and the Psychiatry, Nursing and Midwifery Research Ethics Subcommittee at King's College London (Ref No: 17/18-7807). In addition, the Western Cape Department of Health approved the use of the research sites (Ref No: WC_201807_008). All relevant guidelines, procedures and regulations were followed. Those who participated in the study provided written, informed consent after the procedure had been verbally explained to them. All participants were informed that they were free to withdraw from the study at any time without consequences.

\section{Results}

Semi-structured interviews were conducted with 37 healthcare workers who provided care to pregnant women or managed staff providing the care (Table 1). The majority of healthcare workers were female (91.9\%), older than 35 years (75.7\%), employed by an NPO (56.8\%) and worked at an MOU (67.5\%). 
Table 1

Demographic characteristics of healthcare workers $(n=37)$

\begin{tabular}{|c|c|}
\hline Characteristics & $\begin{array}{l}\text { Healthcare workers } \\
\text { n (\%) }\end{array}$ \\
\hline \multicolumn{2}{|l|}{ Gender } \\
\hline Female & $34(91.9)$ \\
\hline Male & $3(8.1)$ \\
\hline \multicolumn{2}{|l|}{ Age } \\
\hline Under 25 years & $2(5.4)$ \\
\hline $26-35$ years & $7(19.0)$ \\
\hline $36-50$ years & $15(40.5)$ \\
\hline Over 50 years & $13(35.1)$ \\
\hline \multicolumn{2}{|l|}{ Race } \\
\hline White & $3(8.1)$ \\
\hline Coloured* & $28(75.7)$ \\
\hline Black & $6(16.2)$ \\
\hline \multicolumn{2}{|l|}{ Healthcare Worker Role } \\
\hline Manager & $13(35.1)$ \\
\hline Professional healthcare worker & $10(27.0)$ \\
\hline Lay healthcare worker & $14(37.9)$ \\
\hline \multicolumn{2}{|l|}{ Employer } \\
\hline Department of Health & $16(43.2)$ \\
\hline Non-profit Organisation (NPO) & $21(56.8)$ \\
\hline \multicolumn{2}{|l|}{ Employment environment } \\
\hline Facility-based & $25(67.5)$ \\
\hline Community-based & $12(32.5)$ \\
\hline * Individuals of mixed ancestry [ & \\
\hline
\end{tabular}

One hundred and fifty-six pregnant women were screened for symptoms of CMDs and experiences of domestic violence. Thirty-eight women (24\%) screened positive and were invited to participate in a semi- 
structured interview (Table 2). The majority of women interviewed were 26 years or older $(55.2 \%)$ and were unemployed (44.7\%). Almost all the women interviewed scored $\geq 2$ on the psychological distress questionnaire (94.7\%), while $29 \%(n=11)$ scored $\geq 2$ on the domestic violence questionnaire. 
Table 2

Demographic and clinical characteristics of pregnant women $(n=38)$

\begin{tabular}{|c|c|}
\hline Characteristics & $\begin{array}{l}\text { Pregnant Women } \\
\mathrm{n}(\%)\end{array}$ \\
\hline \multicolumn{2}{|l|}{ Age } \\
\hline 15-18 Years & $6(15.8)$ \\
\hline $19-25$ years & $11(29.0)$ \\
\hline $26-35$ years & $17(44.7)$ \\
\hline $36-40$ years & $4(10.5)$ \\
\hline \multicolumn{2}{|l|}{ Race } \\
\hline Coloured* & $26(68.4)$ \\
\hline Black & $12(31.6)$ \\
\hline \multicolumn{2}{|l|}{ Employment status } \\
\hline Employed & $12(31.6)$ \\
\hline Unemployed & $17(44.7)$ \\
\hline Student & $9(23.7)$ \\
\hline \multicolumn{2}{|l|}{ Gestation } \\
\hline First trimester & $15(39.5)$ \\
\hline Second trimester & $19(50.0)$ \\
\hline Third trimester & $4(11.5)$ \\
\hline \multicolumn{2}{|l|}{ Previous pregnancies } \\
\hline None & $10(26.3)$ \\
\hline 1-3 pregnancies & $21(55.3)$ \\
\hline$>3$ pregnancies & $5(18.4)$ \\
\hline Scored $\geq 13$ on EPDS** & $24(63.2)$ \\
\hline Scored $\geq 2$ on the mental health screening questionnaire & $36(94.7)$ \\
\hline Scored $\geq 2$ on domestic violence screening questionnaire & $11(29.0)$ \\
\hline \multicolumn{2}{|l|}{ *Individuals of mixed ancestry [20] } \\
\hline 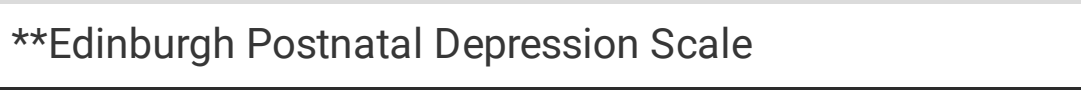 & \\
\hline
\end{tabular}


The facilitators and barriers identified by healthcare workers and pregnant women have been organised into three categories: system-level, provider-level and patient-level (Table 3 ). The facilitators and barriers will be presented under two main headings representative of the stages along the care pathway: (1) detection, and (2) referral and treatment.

Table 3

System-, provider- and patient-level facilitators and barriers to detection, referral and treatment for common mental disorders (CMDs) and experiences of domestic violence

\begin{tabular}{|lll|}
\hline & Facilitators & Barriers \\
\hline Detection of CMDs and experiences of domestic violence & & \\
\hline Availability of a mental health screening questionnaire & System-level & \\
\hline Aspects of the mental health screening questionnaire & & System-level \\
\hline Lack of a domestic violence screening questionnaire & & System-level \\
\hline Perceived importance of detection & $\begin{array}{l}\text { Provider- } \\
\text { level }\end{array}$ & \\
\hline Perceived lack of confidentiality & Patient-level & \\
\hline Heavy workload & & Patient-level \\
\hline Discomfort with mental health issues & & $\begin{array}{l}\text { Provider- } \\
\text { level }\end{array}$ \\
\hline $\begin{array}{l}\text { Referral and treatment of CMDs and experiences of domestic } \\
\text { violence }\end{array}$ & $\begin{array}{l}\text { Provider- } \\
\text { level }\end{array}$ \\
\hline Lack of availability of referral pathways & & \\
\hline Poor awareness of referral pathways & & Patient-level \\
\hline Perceived importance of counselling & & System-level \\
\hline
\end{tabular}

\section{Detection}

\section{Tools for detection}


Varying rates of antenatal mental health and domestic violence screening were reported across the four facilities. The Perinatal Mental Health Project (PMHP) [35] supported one of the facilities by providing an on-site screening and counselling service to all pregnant women attending the MOU for their first antenatal visit. As part of the service, a health promotion officer screened all pregnant women at their first antenatal visit for symptoms of CMDs and the risks thereof. Women who screened positive were referred to the on-site counsellor. The PMHP reported detecting many women with symptoms of depression and anxiety - "I guess six out of ten" (Health Promotion Officer), while the other facilities detected fewer women - "I see two or three on a weekly basis" (Health Promotion Officer), and "It's very rare..." (ANC Nurse). During data collection, an updated version of the Maternity Case Record (MCR) [36] - the national stationery used to record all aspects of the pregnancy - was released. The updated MCR contained a mental health screening tool [26] (the same questionnaire used in this study to detect psychological distress), to be administered by ANC nurses at the patients' first clinic visit.

Detecting women with experiences of domestic violence was less common in all facilities. Healthcare workers reported that they did not specifically enquire about domestic violence and only detected it when a physical examination revealed signs of physical abuse, or when the woman voluntarily disclosed the information. One ANC nurse reported detecting women who were abused "twice or thrice a month", while an MOU manager reported that detecting women who were abused was "not often, but we do". A health promotion officer admitted that if she specifically enquired about domestic violence, she would detect many women as "domestic violence is so high here in this area".

\section{Perceived importance of detection}

All except for one of the facility-based healthcare workers interviewed felt that it was important to screen pregnant women for psychological distress and experiences of domestic violence. One mental health nurse made the link between psychological distress that was left untreated and the consequences to the mother and child by saying: "I think it's very important that these things needs to be picked up because it can only get worse when the baby is born". Many healthcare workers felt that screening should occur at all clinic visits. One ANC nurse mentioned that CMDs could occur at any point during the perinatal period, not just when women attended the MOU for the first time as psychological distress "can start any time during pregnancy".

\section{Perceived lack of confidentiality}

While the majority of pregnant women reported that they would be happy to disclose their feelings and experiences of domestic violence, a few women expressed their concerns regarding confidentiality. One pregnant woman was especially concerned about whether such sensitive information would remain confidential by saying: "... especially in a community where everyone knows everyone, I do not trust them [nurses]". Some healthcare workers also expressed doubts about whether the pregnant women would disclose their feelings by saying: "... remember people put up a nice face hey, they don't want people to know how they feeling" (Breastfeeding Counsellor). 
In the context of the four facilities, many women were financially dependent on their partners, and were concerned about disclosing their experiences of domestic violence. A breastfeeding counsellor explained why women who were abused rarely spoke about their experiences by saying: "Some of them are ashamed that they're actually having to tell you this". One pregnant woman referred to the possible consequences of disclosing her abuse by saying "... so we have to think twice before you do something that you are going to regret".

\section{Heavy workload}

All ANC nurses were concerned about the amount of time it took to assess patients' mental health as their heavy workload and large patient numbers allowed them limited time with each patient. One ANC nurse highlighted her heavy workload in relation to her role as a midwife by saying: "I can't [screen all patients] because now it's gonna take me a long time... then you worry, I need to see the next patient..... so I won't be giving much time to her. I will only just be very...just so, just on the top". In addition, ANC nurses reported feeling concerned that they would not be able to provide a comprehensive consultation if they had the added responsibility of asking women about their mental health. One ANC nurse chose to wait for patients to mention that they were feeling distressed, instead of administering the screening tool to all patients - "if she's not gonna ask you or tell you about her problem then you oversee that -you overlook that, because she looks happy, she's not looking stressful." Many of the ANC nurses were also concerned about the amount of time it took to contain a patient who felt distressed as a result of administering the screening tool. One ANC nurse reflected on her experiences by saying: "sometimes they will start opening up and then it's a problem. You open a can of worms. Cause those questions are thought-provoking....if they're gonna start crying... and then for me it sounds rude to just okay, I'm gonna send you to ...."

\section{Discomfort with mental health issues}

Many ANC nurses felt uncomfortable discussing mental health issues with patients. They thought of themselves as clinicians who were primarily responsible for the physical well-being of the pregnant woman and her foetus, and that they were not trained to adequately address mental health issues. One ANC nurse described the discomfort she experienced when discussing issues related to mental health by saying: "I can talk and everything but there's a point where right, I'm not trained for this ... I don't want to take in so much because it also takes so much out from you". Other healthcare workers were concerned that they were not trained to manage women who screened positive - "if you probe and you ask those three questions [the screening tool], what do you do if the answer is yes?" (ANC Nurse).

\section{Referral and treatment}

\section{Lack of availability of referral pathways}

Referral pathways varied across the four facilities and depended on the issue requiring referral. Patients with depression or anxiety were referred to the mental health nurse, a social worker, a registered psychologist (if available) or to the district hospital, while those who felt suicidal were referred to the mental health nurse, a medical officer, the trauma unit or to a registered psychologist. Women who 
reported experiencing domestic violence were most often referred to the social worker, if one was available. However, specialists such as social workers, mental health nurses and registered psychologists carried a heavy workload and could often only see women who were referred a few weeks later. While some healthcare workers were aware of the referral pathway in their facility, many were not. One lay healthcare worker voiced her uncertainty by saying: "I do not even sometimes know where to refer the mothers to" (HIV Counsellor). The majority of pregnant women were also unaware of how to access mental health care, or whether it was available at the healthcare facilities.

\section{Perceived importance of counselling}

Both healthcare workers and pregnant women thought that providing a counselling service was important. A healthcare worker expressed her thoughts on the importance of counselling by saying: ".... many women who are untreated, or undiagnosed or not caught in the system do end up later on in life here at psychiatry or even with worse symptoms and now it is not only affected themselves but now also the baby after its being born" (Mental Health Nurse). One pregnant woman explained why counselling was important by saying: "I think it would be good, yes, because talking about it makes you feel much better and for me talking to a stranger is much better than talking to people that knows you".

\section{Cultural beliefs and stigma}

While the importance of providing a counselling service was highlighted, healthcare workers also pointed out that many women who were referred for mental health counselling, declined the offer. One ANC nurse explained that mental health issues were stigmatised in the community and that patients were concerned that they would be branded as "...mad if you go for counselling". A lay healthcare worker explained that the community was very small, and that patients were concerned that "... they [neighbours] look at others and they point fingers" (CHW).

Healthcare workers blamed the normalisation of psychological and physical abuse in the community for the poor uptake of referrals by women who were abused, whereas pregnant women attributed their financial dependence on their partner or husband. Healthcare workers thought that women who were abused believed that the abuse was "... how he is showing his love" (Breastfeeding Counsellor), or that he "did not mean to hurt them" (ANC Nurse), or that the women "deserve it" (Breastfeeding Counsellor). One pregnant woman referred to the normalisation of domestic violence in her community by saying: "... it [the abuse] is not a big thing for them [family and friends], because it happens a lot". Many pregnant women who were abused felt that a referral for mental health counselling would not help them as it would not be able to change their dependence on their abusive partners. One pregnant woman explained that she had accepted her abusive relationship by saying: "Everyone mos [anyway] has their own problems ...". Another pregnant woman explained that counselling could not change her situation as "I am not working. He is the breadwinner".

\section{Discussion}


This paper utilizes qualitative semi-structured interviews with healthcare workers and pregnant women, to identify the facilitators and barriers to mental health care for pregnant women attending MOUs in Cape Town. While healthcare workers and pregnant women acknowledged the importance of detecting women with symptoms of depression and anxiety, or experiences of domestic violence, detection rates were low. Barriers contributing to the low detection rates included patients' concerns about the lack of confidentiality and feelings of shame related to experiences of domestic violence; and healthcare workers discomfort in dealing with mental health issues, their limited time available and heavy patient load. Interviews with healthcare workers highlighted the lack of standardised referral pathways and the poor uptake of referrals by women with symptoms of depression and anxiety, or experiences of domestic violence.

Several system-, provider- and patient-level facilitators and barriers were identified. The availability of a mental health screening tool, included in the updated MCR [36] was identified as a system-level facilitator, as it enabled nurses to screen pregnant women for CMDs as part of their routine consultations. However, several system-level barriers linked to the MCR were also identified: the screening tool contains a caveat, indicating that the screening should only be conducted if "resources are available for referral, e.g. mental health nurse, social worker, NPO, medical officer, counsellor, psychiatrists or other services"; the MCR only allows for the screening tool to be completed at the first consultation; and no questions are available to detect experiences of domestic violence [36]. As depression and anxiety may develop [24] and remit [37] at any point during the perinatal period, only administering the screening tool at the first clinic visit, would result in missed opportunities for care for women who develop symptoms of depression or anxiety later in their pregnancy, or after birth. While the MCR provides a list of counselling topics, including one for domestic violence, the lack of a screening question for detecting domestic violence could be responsible for the poor detection rates found in communities where domestic violence is prevalent [24, 38], as studies suggest that routine screening for domestic violence in primary healthcare settings improves detection $[39,40]$. The final system-level barrier contributing to the low detection and referral rate, was the lack of standardised referral pathways. We found that both healthcare workers and pregnant women were unclear about how and where to access care. As the mental health screening tool was only to be conducted when resources were available, healthcare workers who were unaware of resources available in the facility, were free to opt out of providing the screening service to perinatal women.

Provider-level facilitators included the perceived importance of detecting pregnant women with CMDs and experiences of domestic violence, and the treatment of women who screened positive. In this study, healthcare workers acknowledged the importance of providing a screening, referral and counselling service. However, several provider-level barriers were identified. ANC nurses who were tasked with conducting the screening felt that they were not the right cadre of staff to provide the service, citing their large patient load, the additional time needed to screen patients, their lack of awareness of the referral pathway, and their discomfort with mental health issues as the primary reasons for their reluctance. Studies investigating the challenges to providing quality healthcare in South Africa have highlighted the shortage of healthcare workers, especially at the nursing level in urban areas [41]. As it is unconstitutional to deny anyone access to basic healthcare in public healthcare facilities in South Africa [42], these 
facilities are often overcrowded with inadequate staff and resources available to provide quality care to all [41]. However, this situation is not unique to South Africa. In Zimbabwe, provider-level barriers to screening perinatal women attending PHC facilities for depression included nurses' lack of time and inadequate training, and lack of privacy making patients less likely to disclose psychological distress [43]. While the lack of privacy was not identified as a barrier in the facilities included in this study, it is a challenge in other PHC facilities in South Africa [44]. Similar findings were reported in a review of studies exploring healthcare workers perceived barriers to screening, referral and management of mental health issues in perinatal women [45], and in reviews of barriers to IPV screening as perceived by healthcare providers [46-48]. Studies highlighted time constraints, lack of knowledge and training, and insufficient awareness of referral pathways as key provider-level barriers to screening.

Patient-level facilitators included the perceived importance of screening and counselling, while the patient-level barriers included concerns regarding confidentiality when disclosing sensitive information. High levels of mental health stigma have been reported in South Africa. In a qualitative study exploring the experiences of mental health stigma among healthcare providers and users in the North West province of South Africa [49], the authors reported that users were exposed to stigmatising attitudes of family members, neighbours, friends, church members and the general community. Similarly, a study in Massachusetts USA reported that perinatal women were reluctant to disclose their mental health issues due to stigma and the fear of being judged as an unfit parent, resulting in missed appointments and poor uptake of services [46].

Our study has strengths and limitations. We have both the perceptions of service providers and service users from the same clinics. However, our service users were interviewed when attending the clinic for their first antenatal appointment, making it difficult to link their perceptions of care with the specific healthcare providers we interviewed. Our study may be limited by social desirability bias, especially regarding the pregnant women's responses to questions on domestic violence, and service providers' responses to their role in providing care.

Several strategies can be used to mitigate the challenges we have identified and strengthen the health system. ANC nurses require training on administering the screening tool to decrease their feelings of discomfort with mental health issues. As nurses' time with patients is limited, the mental health screening questionnaire could be administered in a patient centred manner [50]. ANC nurses could be trained to routinely enquire about their patients' feelings and anxieties while examining them, instead of completing the screening tool as a ticking exercise while completing the required documentation linked to the consultation. Standardised referral pathways and processes, specific to each facility, need to be developed and disseminated widely to ensure that both healthcare workers and patients are aware of the services available and how to access them. To lessen the burden of specialised mental healthcare providers such as social workers and mental health nurses, a cadre of lay healthcare workers could be identified and trained to provide basic evidence-based problem-solving counselling [51] to women with mild symptoms of depression or anxiety. The limitations of the MCR will need to be addressed at a policy level to encourage healthcare providers to detect symptoms of depression, anxiety and experiences of 
domestic violence in all pregnant women, at all clinic visits. Intervention studies aimed at strengthening the healthcare system with regards to detection, referral and treatment at MOUs in South Africa are needed.

\section{Conclusions}

Facilitators identified by healthcare workers and pregnant women included the importance of detecting women with symptoms of CMDs and experiences of domestic violence and the availability of a mental health screening tool, yet detection rates at the MOUs were low. Several barriers were identified - at the system-level, these related to aspects of the screening tool, and the lack of a screening questionnaire to identify experiences of domestic violence. Provider-level barriers included healthcare workers discomfort in dealing with mental health issues, their limited time available, heavy patient load and lack of awareness of available referral pathways. Patient-level barriers included patients' concerns about the lack of confidentiality, and feelings of shame related to experiences of domestic violence. While the systemlevel barriers need to be addressed at a policy level, the patient- and provider-level barriers will be used by the ASSET study to inform the development of a health systems strengthening intervention, to be piloted in MOUs and basic antenatal care clinics in Cape Town.

\section{Abbreviations}

ANC - antenatal care

ASSET - Health system strengthening in sub-Saharan Africa

CHW - community health worker

CMD - common mental disorders

DoH - Department of Health

EPDS - Edinburgh postnatal depression scale

LMIC - low- and middle-income countries

MOU - midwife obstetric unit

MRC - maternity case record

NPO - not-for-profit organisation

OTL - outreach team leader

$\mathrm{PHC}$ - primary healthcare 


\section{Declarations}

\section{Ethical approval and consent to participate}

Ethical approval for the study was obtained from the Human Research Ethics Committee at the University of Cape Town (Ref No: 139/2018) and the Psychiatry, Nursing and Midwifery Research Ethics Subcommittee at King's College London (Ref No: 17/18-7807). In addition, the Western Cape Department of Health approved the use of the research sites (Ref No: WC_201807_008). Those who participated in the study provided written, informed consent after the procedure had been verbally explained to them. All participants were informed that they were free to withdraw from the study at any time without consequences.

\section{Consent for publication}

Not applicable

\section{Availability of data and materials}

The datasets used and/or analysed during the current study are available from the corresponding author on reasonable request.

\section{Competing interests}

The authors declare that they have no competing interests

\section{Funding}

This work was supported by the National Institute for Health Research (NIHR) Global Health Research Unit on Health System Strengthening in Sub-Saharan Africa, King's College London [GHRU 16/136/54].

\section{Authors' contributions}

ZA, SB, MS, SH and CL provided input in the design of the study. ZA managed the data collection and developed the coding framework. ZA and SB analysed the qualitative interviews. ZA performed the data analysis and prepared the first draft of the manuscript. SB, MS, SH and CL reviewed the manuscript and providing input. All authors approved the final version of the manuscript.

\section{Acknowledgements}

We are grateful to the healthcare workers and pregnant women who participated in the study for generously giving their time and energy to complete interviews.

\section{References}


1. Woody C, Ferrari A, Siskind D, Whiteford H, Harris M. A systematic review and meta-regression of the prevalence and incidence of perinatal depression. J Affect Disord 2017,219:86-92.

2. Dennis $C$, Falah-Hassani K, Shiri R. Prevalence of antenatal and postnatal anxiety: systematic review and meta-analysis. The British Journal of Psychiatry 2017,210(5):315-323.

3. Redinger S, Norris S, Pearson R, Richter L, Rochat T. First trimester antenatal depression and anxiety: prevalence and associated factors in an urban population in Soweto, South Africa. Journal of developmental origins of health and disease 2018,9(1):30-40.

4. Hartley M, Tomlinson M, Greco E, Comulada WS, Stewart J, Le Roux I, et al. Depressed mood in pregnancy: prevalence and correlates in two Cape Town peri-urban settlements. Reproductive health 2011,8(1):9.

5. Manikkam L, Burns JK. Antenatal depression and its risk factors: an urban prevalence study in KwaZulu-Natal. South African Medical Journal 2012,102(12):940-944.

6. Abrahams Z, Lund C, Field S, Honikman S. Factors associated with household food insecurity and depression in pregnant South African women from a low socio-economic setting: a cross-sectional study. Soc Psychiatry Psychiatr Epidemiol 2018,53(4):363-372.

7. van Heyningen T, Honikman S, Myer L, Onah MN, Field S, Tomlinson M. Prevalence and predictors of anxiety disorders amongst low-income pregnant women in urban South Africa: a cross-sectional study. Archives of women's mental health 2017,20(6):765-775.

8. Rahman A, Bunn J, Lovel H, Creed F. Association between antenatal depression and low birthweight in a developing country. Acta Psychiatr Scand 2007,115(6):481-486.

9. Gelaye B, Rondon MB, Araya R, Williams MA. Epidemiology of maternal depression, risk factors, and child outcomes in low-income and middle-income countries. The Lancet Psychiatry 2016,3(10):973982.

10. Jarde A, Morais M, Kingston D, Giallo R, MacQueen GM, Giglia L, et al. Neonatal outcomes in women with untreated antenatal depression compared with women without depression: a systematic review and meta-analysis. JAMA psychiatry 2016,73(8):826-837.

11. Rahman A, Fisher J, Bower P, Luchters S, Tran T, Yasamy MT, et al. Interventions for common perinatal mental disorders in women in low-and middle-income countries: a systematic review and meta-analysis. Bull World Health Organ 2013,91:593-6011.

12. Baranov V, Bhalotra S, Biroli P, Maselko J. Maternal depression, women's empowerment, and parental investment: evidence from a randomized controlled trial. Am Econ Rev 2020,110(3):824-859.

13. Tomlinson M, O'Connor MJ, Le Roux IM, Stewart J, Mbewu N, Harwood J, et al. Multiple risk factors during pregnancy in South Africa: the need for a horizontal approach to perinatal care. Prevention Science 2014,15(3):277-282.

14. Department of Health. National Mental Health Policy Framework and Strategic Plan, 2013-2020 . 2013.

15. World Health Organisation. Zero Draft Global Mental Health Action Plan 2013 - 2020. 2012. 
16. Docrat S, Besada D, Cleary S, Daviaud E, Lund C. Mental health system costs, resources and constraints in South Africa: a national survey. Health Policy Plan 2019,34(9):706-719.

17. English R, Peer N, Honikman S, Tugendhaft A, Hofman KJ. 'First 1000 days' health interventions in low-and middle-income countries: alignment of South African policies with high-quality evidence. GLOBAL HEALTH 2017,10:1340396.

18. ASSET. Maternal mental health and violence against women in South Africa. 2020, Available at: https://healthasset.org/wp6/. Accessed September/29, 2020.

19. South African History Online. Cape Flats, Cape Town. 2020, Available at: https://www.sahistory.org.za/place/cape-flats-cape-town. Accessed September/15, 2020.

20. Adhikari M. Not white enough, not black enough: Racial identity in the South African coloured community. : Ohio University Press, 2005.

21. Statistics South Africa. Poverty trends in South Africa: An examination of absolute poverty between 2006 and 2015. 2017.

22. Pluddemann A. The SACENDU project: monitoring alcohol and drug abuse trends in South Africa. International Journal of Psychology 2012,47.

23. Maringira G, Masiya T. Persistence of Youth Gang Violence in South Africa. The African Review 2018,45:164-179.

24. Malan M, Spedding MF, Sorsdahl K. The prevalence and predictors of intimate partner violence among pregnant women attending a midwife and obstetrics unit in the Western Cape. Global Mental Health 2018,5.

25. Cox JL, Holden JM, Sagovsky R. Detection of postnatal depression: development of the 10-item Edinburgh Postnatal Depression Scale. Br J Psychiatry 1987,150(6):782-786.

26. Abrahams Z, Schneider M, Field S, Honikman S. Validation of a brief mental health screening tool for pregnant women in a low socio-economic setting. BMC psychology 2019,7(1):77.

27. Lawrie T, Hofmeyr G, De Jager M, Berk M. Validation of the Edinburgh Postnatal Depression Scale on a cohort of South African women. S Afr Med J 1998,88(10):1340-1344.

28. De Bruin GP, Swartz L, Tomlinson M, Cooper PJ, Molteno C. The factor structure of the Edinburgh Postnatal Depression scale in a South African peri-urban settlement. S Afr J Psychol 2004,34(1):113121.

29. Whooley M. Whooley questions for depression screening. 2016, Available at: http://whooleyquestions.ucsf.edu/. Accessed February/27, 2018.

30. Skapinakis P, Kroenke K, Spitzer R, Williams J. The 2-item Generalized Anxiety Disorder scale had high sensitivity and specificity for detecting GAD in primary care. Evid Bas Med 2007,12(5):149.

31. Gale NK, Heath G, Cameron E, Rashid S, Redwood S. Using the framework method for the analysis of qualitative data in multi-disciplinary health research. BMC medical research methodology 2013,13(1):1-8.

32. Bazeley P, Jackson K. Qualitative data analysis with NVivo. 2013. 
33. Gwet KL. Handbook of inter-rater reliability: The definitive guide to measuring the extent of agreement among raters. : Advanced Analytics, LLC, 2014.

34. Klein D. Implementing a general framework for assessing interrater agreement in Stata. The Stata Journal 2018,18(4):871-901.

35. Honikman S, Van Heyningen T, Field S, Baron E, Tomlinson M. Stepped care for maternal mental health: a case study of the perinatal mental health project in South Africa. PLoS Med 2012,9(5):e1001222.

36. Department of Health. Maternity Case Record. 2018, Available at: https://pmhp.za.org/wpcontent/uploads/Western-Cape-Maternity-Case-Record-Version-19-June-2018.pdf. Accessed March/23, 2020.

37. Garman EC, Schneider M, Lund C. Perinatal depressive symptoms among low-income South African women at risk of depression: trajectories and predictors. BMC pregnancy and childbirth 2019,19(1):202.

38. Field S, Onah M, van Heyningen T, Honikman S. Domestic and intimate partner violence among pregnant women in a low resource setting in South Africa: a facility-based, mixed methods study. BMC Womens Health 2018,18(1):1-13.

39. Chen P, Rovi R, Pan K, Johnson M. Costs Effectiveness of Domestic Violence Screening in Primary Care Settings: A Comparison of 3 Methods. J Community Med Health Educ 2013,3(253):21610711.1000253.

40. Sivarajasingam V. Routine screening for domestic abuse. British Journal of General Practice 2021,71(705):173-173.

41. Maphumulo WT, Bhengu BR. Challenges of quality improvement in the healthcare of South Africa post-apartheid: A critical review. Curationis 2019,42(1):1-9.

42. Coovadia H, Jewkes R, Barron P, Sanders D, McIntyre D. The health and health system of South Africa: historical roots of current public health challenges. The Lancet 2009,374(9692):817-834.

43. January J, Chimbari MJ. Opportunities and obstacles to screening for perinatal depression among women in Zimbabwe: A narrative review of literature. South African Journal of Psychiatry 2018,24.

44. Drigo L, Luvhengo M, Lebese RT, Makhado L. Attitudes of Pregnant Women Towards Antenatal Care Services Provided in Primary Health Care Facilities of Mbombela Municipality, Mpumalanga Province, South Africa. The Open Public Health Journal 2020,13(1).

45. Bayrampour $\mathrm{H}$, Hapsari AP, Pavlovic J. Barriers to addressing perinatal mental health issues in midwifery settings. Midwifery 2018,59:47-58.

46. Byatt N, Biebel K, Lundquist RS, Moore Simas TA, Debordes-Jackson G, Allison J, et al. Patient, provider, and system-level barriers and facilitators to addressing perinatal depression. Journal of Reproductive and Infant Psychology 2012,30(5):436-449.

47. Waalen J, Goodwin MM, Spitz AM, Petersen R, Saltzman LE. Screening for intimate partner violence by health care providers: barriers and interventions. Am J Prev Med 2000,19(4):230-237. 
48. Sprague S, Madden K, Simunovic N, Godin K, Pham NK, Bhandari M, et al. Barriers to screening for intimate partner violence. Women Health 2012,52(6):587-605.

49. Egbe CO, Brooke-Sumner C, Kathree T, Selohilwe O, Thornicroft G, Petersen I. Psychiatric stigma and discrimination in South Africa: perspectives from key stakeholders. BMC Psychiatry 2014,14(1):1-14.

50. Kitson A, Marshall A, Bassett K, Zeitz K. What are the core elements of patient-centred care? A narrative review and synthesis of the literature from health policy, medicine and nursing. J Adv Nurs 2013,69(1):4-15.

51. Boisits S, Abrahams Z, Schneider M, Honikman S, Kaminer D, Lund C. Developing a task-sharing psychological intervention to treat mild to moderate symptoms of perinatal depression and anxiety in South Africa: a mixed-method formative study. International Journal of Mental Health Systems 2021,15(1):1-14.

\section{Supplementary Files}

This is a list of supplementary files associated with this preprint. Click to download.

- SupplementaryFile1 Interviewquestionshealthcareworkers.docx

- SupplementaryFile2Interviewquestionsforpregnantwomen.docx 